\title{
Ethics, geological risks, politics and society
}

\author{
A. Cecioni \& V. Pineda \\ Departamento Ciencias de la Tierra, Universidad de Concepción, Chile
}

\begin{abstract}
Since humans live in communities, the moral regulation of behavior has been necessary for the collective well-being. From the antiquity, the Greek philosophers discussed moral behavior, which led to the later development of ethics.

Some geological processes, such as earthquakes, tsunami, landslides, volcanism, and geological structures such as faults, are potentially hazardous for the inhabitants. Some geological processes can affect entire cities and active faults can damage buildings constructed on them.

In general, the urban and urban development areas are sustained on numerous components. Among these components can be pointed out the economic one that regulates the urban already consolidated zone and the areas of urban expansion; the information provided by geologists about the possible occurrence of geologically hazardous or risky processes; and the political authorities that must take the difficult decisions based on the economic component of the private investors, the geologically dangerous processes and the commitment of the State to provide inexpensive accommodation to low social-economic people and the responsibility of granting safety to the society.

Analysis and questions about professional ethics, investors' ethics and political ethics of the State, taking as a goal the information that must be provided to the citizenship and to the civil protection, are discussed.
\end{abstract}

Keywords: ethic, geological risks, land planning.

\section{Introduction}

Ethics (gr. êthos) is the support of the principles of the human behavior, called also morality (lat. moralis).

Ethics is the natural norm of the human conduct. Since the peoples live in community, the moral regulation of the conduct has been necessary to obtain the collective well-being. 
Among the classic civilizations, the Egyptian developed the ethics combined with the religion; in classic China culture Confucio's doctrine was accepted as a morality code. From the $\mathrm{VI}^{\text {th }}$ century B.C., the Greek philosophers, thought about the moral conduct, developing the ethics as a way of personal life related to the respect for the social community.

Socrates did not partake the ideas of the sophists. His philosophical position it is represented in the dialogues of his disciple Plato. The Socratic vision can be summarized in the following concepts: the virtue is knowledge; the people will be virtuous if it has instruction and culture, and the vice (evil) it is the fruit of the ignorance. According to Plato, the human soul is composed by three components: the intellect, the determination ("the want") and the emotion. The virtue of the intellect is the knowledge of the intentions of the life; the determination has the virtue of the value in the aptitude for acting; and the virtue of emotion it is the prudence. Plato thinks that the real reality is the purification of all the passions, which originates knowledge, temperance, justice and virtue [1] talents that he reiterate in his works. Plato has an absolute conception of the "good" and of the virtues of the ethical and moral attitudes.

Christianity extended the application of the moral values to the whole society, including the slaves. This conception of equality in agree to the ethics and to the morality, is represented in several references and concepts, such as loves your neighbor as to you itself [2].

It is interesting to observe the masterly classification of the faults that Dante Alighieri describes in the Chapter of the Hell of the Divine Comedy [3]. He places the more condemnable attitudes between $7^{\text {th }}$ and $9^{\text {th }}$ circle of the Hell; the violent ones against God, against the nature and against the society imprisoned in the seventh circle; and the traitors to their benefactors condemned to the ninth circle. Then, according to Dante, we have that the treason and the lack of ethics and of morality, are located in the maximum circles of punishment.

For need of living together, there were formed groups of persons that constitute the society. The city represents the symbol of the social collectivity. From the first cultures and men's groups, the city constitutes a living space in which the society feels protected. In the city there develop the economic, cultural and family activities. Consequently, to be able to coexist, the persons must act with ethics and be mutually respectful. Leaders and scientists are not exempt from the ethical duty towards the society.

The society must be regulated in the ethics and morality conditions. Institutions and laws were created. But the laws become anachronistic, since they are applied to a way of life and of attitudes that happen in a certain temporary and circumstantial episode. If this social situation is overcome, the law remains obsolete. It is very difficult to be able to establish laws on events that might happen in certain future circumstances, in conditions that we do not know. The serious problem is not to legislate and not to take decisions related to situations that we know, that can happen and that are hazardous for the safety of the society.

In this respect, no person has the right to damage other one, understanding the damage in all the possible forms. The duties and the rights exist. One of the 
principal duties is the honest and complete information, since giving only a part of the truth is a falsehood. One of the principal rights is the attribution of living safely, and this is an obligation of the State.

Politics, science and society must constitute a harmonic whole founded on the ethics.

\section{Geological hazards and some related question: Concepción area as a pattern}

In Concepción (South-Central Chile) area, that could be a case of other similar regions of other countries, there occur constructions that are founded on faults, in zones of flood for tsunami and/or that can be affected by landslides. This situation causes a decrease of the quality of life and a dangerousness situation for the inhabitants.

It is thus convenient to design and apply procedures for determining responsibilities. At this point, we must consider some questions related to (A) all ready constructed areas, and (B) use of expansion urban areas.

(A) For already constructed areas, some questions are:

- Who is the responsible to notify to the inhabitants of a building that it is constructed over a fault that could damage the building in case of an earthquake?

- Who is the responsible to notify to the inhabitants that the coastal zone in which they live or work is dangerous for tsunami hazard?

- Who is the responsible to notify to the inhabitants that the area where they live or work could be destroyed by a tsunami?

- Who is the responsible to notify to the tourist skiers that the volcano where they are is not monitored?

(B) For expansion urban areas:

- Who is the responsible to approve the use of a certain hazardous areas for general social benefit?

- Who is the responsible to consent the construction of a building on a fault?

- Knowing the dangerousness of some area, who is responsible to accept the proposal of an investor, which have, obviously, an economic interest to develop constructions?

- Who is the responsible to request information of hazard natural processes, vulnerability and risk of some areas?

In the area of Concepción there are active faults, some zones with high seismic risk (Fig. 1), landslide risk (Fig. 2) and tsunami risk [4] (Fig. 3).

\section{Some answers}

Answers to these questions could be very complicate for some ones. But applying ethics, the solution is simple. 
10 Geo-Environment and Landscape Evolution II

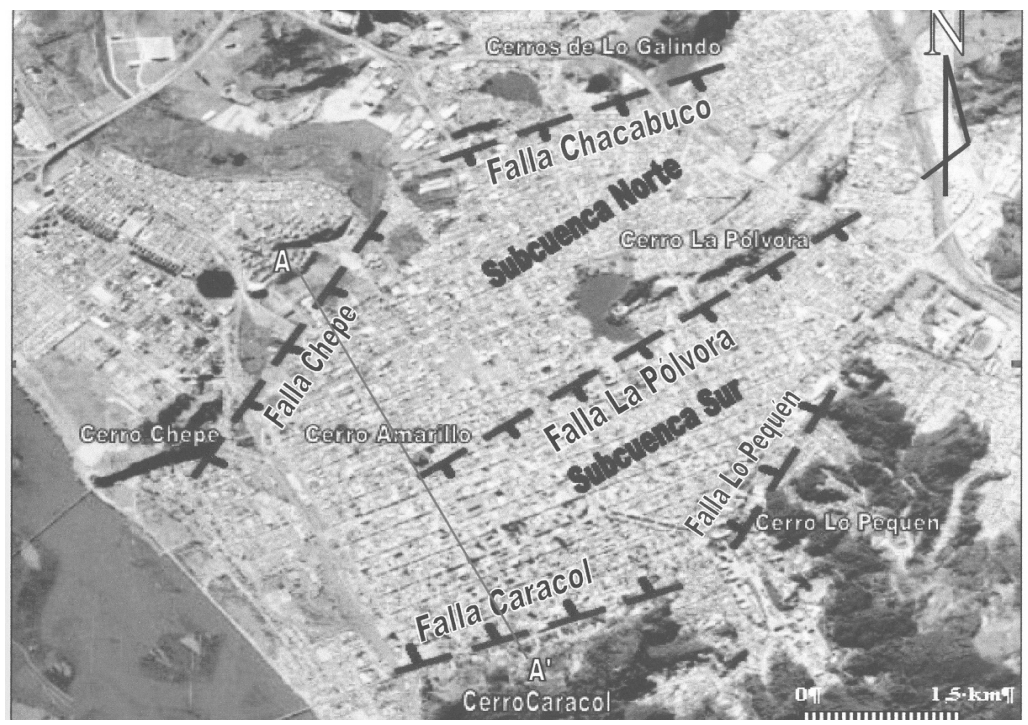

(A)

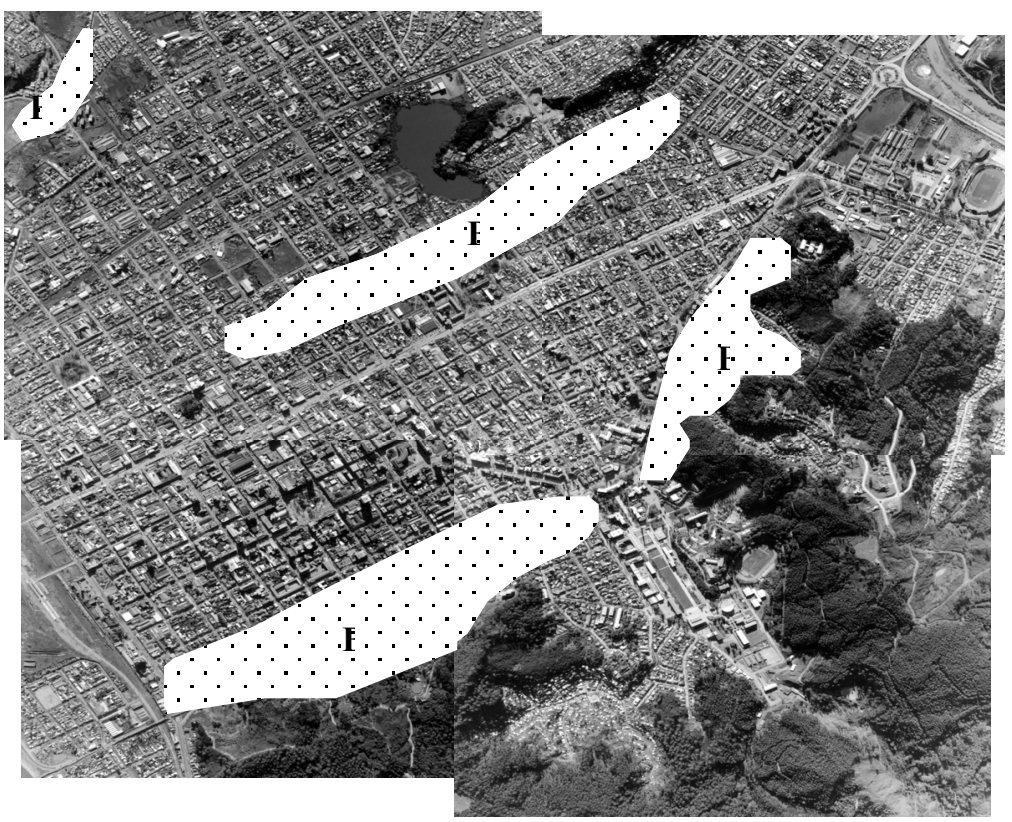

(B)

Figure 1: (A) Main faults in Concepción city. (B) Zones of major seismic dangerousness, considering faulting, soil, underground waters and other geological factors. 
Geo-Environment and Landscape Evolution II 11

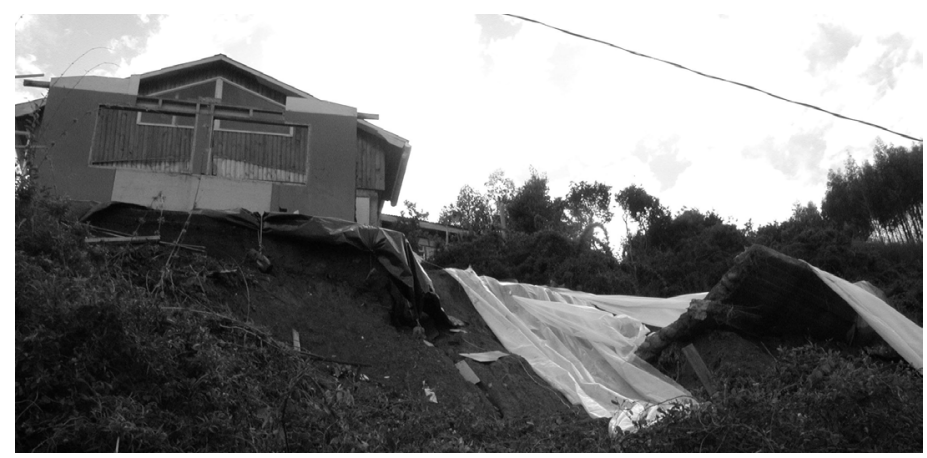

(A)

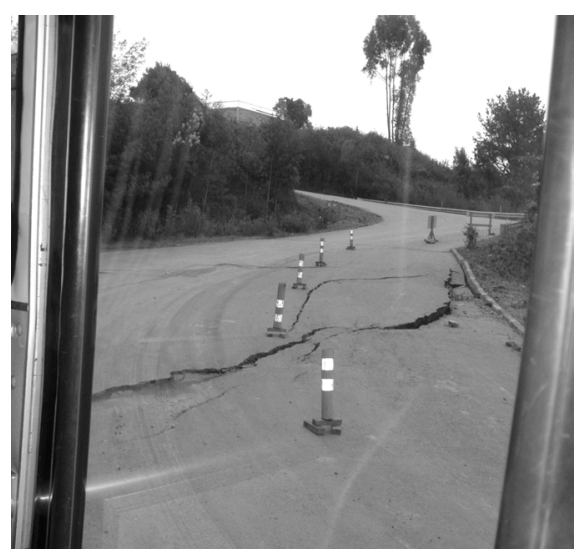

(B)

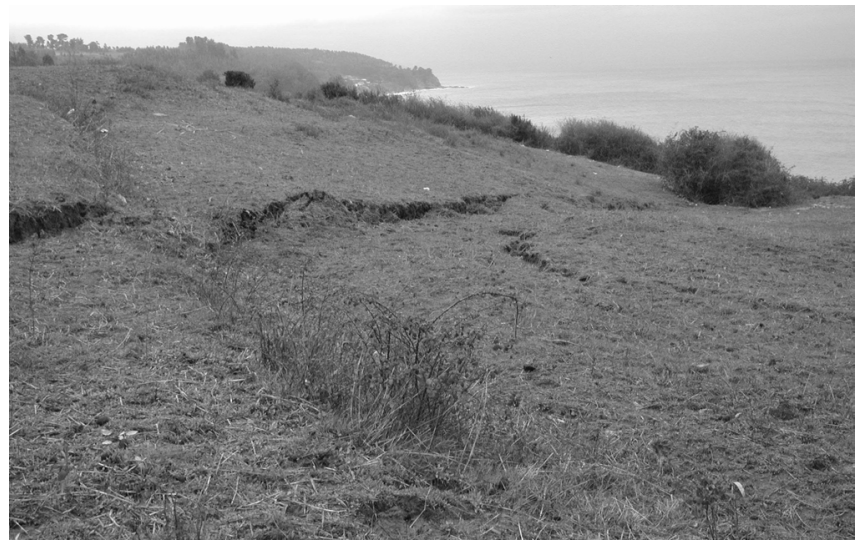

(C)

Figure 2: (A) Landslide in zones of housings. (B) Slide in mountain highway. (C) Crown of new landslides (retrogresives) - hazardous zone. 


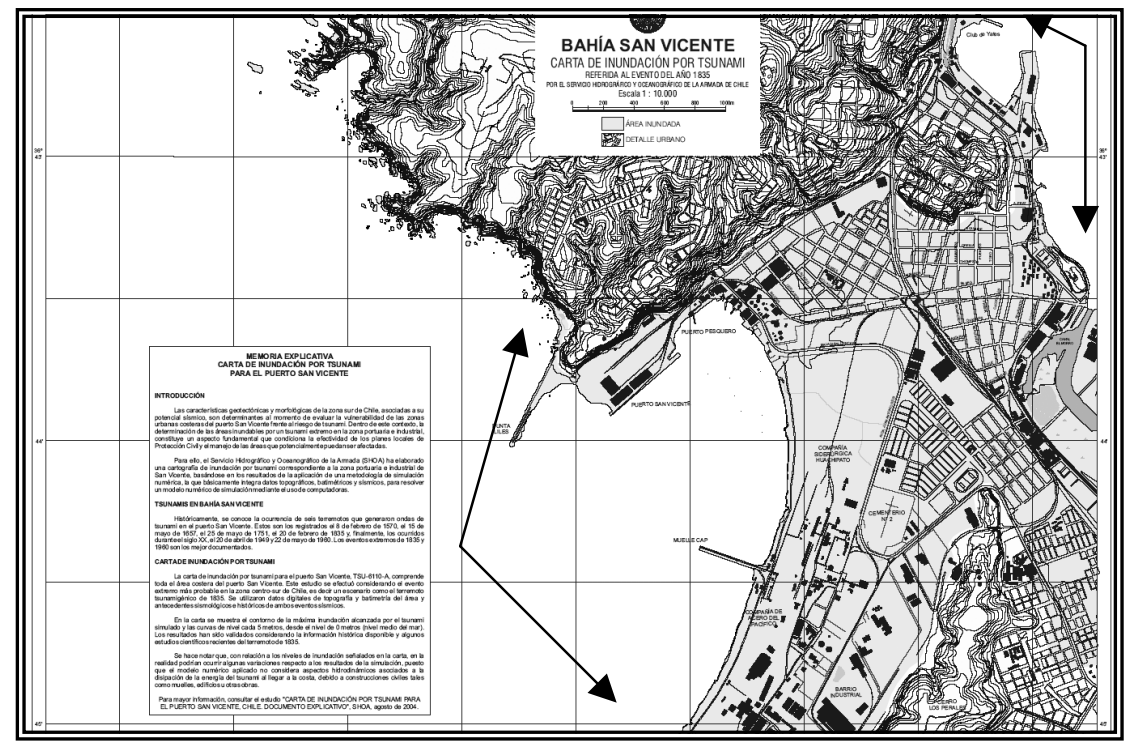

Figure 3: Zone of flood by tsunami indicated with light gray colour, extending across the whole city of Talcahuano.

The occupation of an investor is to make investments to develop social activities, for which it is normal to expect economic benefits. Scientists must don't have conflict of interests and its role is to study neatly the territory, analyze in an objective way the hazardousness and associate risks, prepare maps of vulnerability and to warn the authorities about these dangers. The politicians and managers of the State, as the scientists, must not have created interests and they has the obligation to be informed about the geological and natural risks, in general, before granting the permissions of urban development.

Consequently, the administrator of the State must warn the population about the dangers and risks of geological processes that could occur in the areas where they live and work. Additionally, the administrators must evaluate the convenience of authorize investor to occupies territories for some social activities. On the other hand, the administrators of the State must request studies of vulnerability of geological risks that allow to carry out a suitable managing of the territory and, in the case that some dangerous zone should be occupied for urbanism, industry and tourism, among others, they will have to request and finance a appropriate monitoring system for the geological hazardous processes that affect this territorial space.

\section{Thoughts and conclusions}

In several countries there do not exist procedure that force to the State to effect studies of vulnerability, risk and monitoring of geological hazardous processes. 
The State provides ambulances and hospitals to care patients who have accidents; it provides policemen to protect the citizens of the delinquency; it provides firemen to attack fires and to carry out rescues. Then, why the State does not place in the same plane the geological hazardous processes and provides to the society of a strategy of monitoring intended to save lives?

We are strongly sure that an international organization must demand to the States the application of studies on geological hazardous processes and to carry out an ethical planning of the territory, in order that the society could feel surer of living in an environment in which these processes are monitored.

\section{References}

[1] Platón. Diálogos Socráticos. Traducción de Patricio de Azcárate. Editorial Océano de México. S.A. 365 p.

[2] Sagrada Biblia. Biblioteca de Autores Cristanos, de la Editorial Católica, S.A. Madrid 1970. Cuarta Edición. San Lucas (10:27). 1377 p.

[3] Dante Alighieri. La Divina Comedia. Adapt. Francisco José Fernández Defez - México, D.F.: Editorial Selector, S.A. de C.V., 2004. 96 p.

[4] Servicio Hidrográfico y Oceanográfico de la Armada de Chile. Bahía de San Vicente. Carta de Inundación por tsunami, escala 1:10.000. Armada de Chile, SHOA, 2000. 